\title{
The $(G>A)$ rs11573191 Polymorphism of PLA2G5 Gene Is Associated with Premature Coronary Artery Disease in the Mexican Mestizo Population: The Genetics of Atherosclerotic Disease Mexican Study
}

\author{
Gilberto Vargas-Alarcón, ${ }^{1}$ Carlos Posadas-Romero, ${ }^{2}$ Teresa Villarreal-Molina, ${ }^{3}$ \\ Edith Alvarez-León, ${ }^{1}$ Javier Angeles-Martinez, ${ }^{1}$ María Elena Soto, ${ }^{4}$ Irma Monroy-Muñoz, ${ }^{1}$ \\ Juan Gabriel Juárez, ${ }^{2}$ Carlos Jerges Sánchez-Ramírez, ${ }^{1}$ Julian Ramirez-Bello, ${ }^{5}$ \\ Silvestre Ramírez-Fuentes, ${ }^{1}$ José Manuel Fragoso, ${ }^{1}$ and José Manuel Rodríguez-Pérez ${ }^{1}$ \\ ${ }^{1}$ Departments of Molecular Biology, Endocrinology, and Immunology, National Institute of Cardiology Ignacio Chávez, \\ 14080 Mexico City, DF, Mexico \\ ${ }^{2}$ Department of Endocrinology, National Institute of Cardiology Ignacio Chávez, Juan Badiano 1, Sección XVI, Tlalpan, \\ 14080 Mexico City, DF, Mexico \\ ${ }^{3}$ Cardiovascular Genomics Laboratory, National Institute of Genomic Medicine, 14610 Mexico City, DF, Mexico \\ ${ }^{4}$ Department of Immunology, National Institute of Cardiology Ignacio Chávez, Juan Badiano 1, Sección XVI, Tlalpan, \\ 14080 Mexico City, DF, Mexico \\ ${ }^{5}$ Laboratory of Genomic Medicine, Research Unit, Juárez de México Hospital, 07760 Mexico City, DF, Mexico
}

Correspondence should be addressed to Gilberto Vargas-Alarcón; gvargas63@yahoo.com

Received 19 February 2014; Revised 2 May 2014; Accepted 4 May 2014; Published 18 May 2014

Academic Editor: Terry K. Smith

Copyright (C) 2014 Gilberto Vargas-Alarcón et al. This is an open access article distributed under the Creative Commons Attribution License, which permits unrestricted use, distribution, and reproduction in any medium, provided the original work is properly cited.

Coronary artery disease (CAD) is a multifactorial disorder that results from an excessive inflammatory response. Secretory phospholipase $\mathrm{A}_{2}-\mathrm{V}\left(\mathrm{sPLA}_{2}-\mathrm{V}\right)$ encoded by PLA2G5 gene promotes diverse proinflammatory processes. The aim of the present study was to analyze if PLA2G5 gene polymorphisms are associated with premature CAD. Three PLA2G5 polymorphisms (rs11573187, rs2148911, and rs11573191) were analyzed in 707 patients with premature CAD and 749 healthy controls. Haplotypes were constructed after linkage disequilibrium analysis. Under dominant, recessive, and additive models, the rs11573191 polymorphism was associated with increased risk of premature $\mathrm{CAD}\left(\mathrm{OR}=1.51, P_{\mathrm{dom}}=3.5 \times 10^{-3} ; \mathrm{OR}=2.95, P_{\text {rec }}=0.023 ; \mathrm{OR}=1.51, P_{\text {add }}=1.2\right.$ $\left.\times 10^{-3}\right)$. According to the informatics software, this polymorphism had a functional effect modifying the affinity of the sequence by the MZF1 transcription factor. PLA2G5 polymorphisms were in linkage disequilibrium and the CGA haplotype was associated with increased risk of premature $\mathrm{CAD}(\mathrm{OR}=1.49, P=0.0023)$ and with hypertension in these patients $(\mathrm{OR}=1.75, P=0.0072)$. Our results demonstrate the association of the PLA2G5 rs11573191 polymorphism with premature CAD. In our study, it was possible to distinguish one haplotype associated with increased risk of premature CAD and hypertension.

\section{Introduction}

Coronary artery disease (CAD) is a complex multifactorial and polygenic disorder resulting from an excessive inflammatory response to various forms of injurious stimuli to the arterial wall [1-3]. Although the precise mechanisms responsible for the onset of the disease are still unknown, multiple genetic factors may cooperate with environmental factors to confer susceptibility to CAD. The secretory phospholipase $\mathrm{A}_{2}$ $\left(\mathrm{sPLA}_{2}\right.$ ) family of enzymes hydrolyzes the sn-2 ester bond of phospholipids and cell membranes, generating nonesterified free fatty acids and lysophospholipids, which may promote diverse proinflammatory processes [4]. 
Ten sPLA 2 enzymes have been described in humans and four of them (sPLA ${ }_{2}$-IIA, sPLA - III, $\mathrm{PLA}_{2}-\mathrm{V}$, and $s \mathrm{PLA}_{2}-$ $\mathrm{X})$ have been implicated in atherosclerosis [5-11]. Hydrolysis by $\mathrm{sPLA}_{2}-\mathrm{V}$ reduces the capacity of HDL to promote cellular cholesterol efflux from lipid-loaded macrophages [12]. Some experiments have shown that LDL hydrolyzed by $\mathrm{SPLA}_{2}-\mathrm{V}$ induces foam cell formation in mouse peritoneal macrophages $[6,7]$. On the other hand, immunohistochemical analysis has shown $\mathrm{sPLA}_{2}-\mathrm{V}$ to be associated with smooth muscle cells and foam cells in the lipid cores of both human and mouse atherosclerotic lesions [13]. The sPLA $2-\mathrm{V}$ is encoded by the PLA2G5 gene located in chromosome 1p3436.1 [14]. Polymorphisms in this gene have been reported and some of them have been associated with LDL and oxLDL levels in a group of patients with type II diabetes mellitus [15]. These data suggest that the gene that encodes $\mathrm{SPLA}_{2}-$ $\mathrm{V}$ could be an important candidate gene to be studied in atherosclerosis. The aim of the present study was to analyze if PLA2G5 gene polymorphisms are associated with premature coronary artery disease (CAD) in a case-control association study (GEA or genetics of atherosclerotic disease).

\section{Material and Methods}

The primary aim of the GEA study is to investigate genetic factors associated with premature CAD and other coronary risk factors in the Mexican population. The study complies with the Declaration of Helsinki. All participants provided written informed consent, and the study was approved by the Ethics Committees of the Instituto Nacional de Cardiología "Ignacio Chávez" and the Instituto Nacional de Medicina Genómica.

2.1. Subjects. All GEA participants are unrelated and of selfreported Mexican-Mestizo ancestry (three generations). A Mexican Mestizo is defined as someone born in Mexico, who is a descendant of the original autochthonous inhabitants of the region and of individuals, mainly Spaniards, of Caucasian and/or African origin, who came to America during the sixteenth century. The study included 707 patients with premature CAD and 749 healthy controls from the genetics of atherosclerotic disease (GEA) Mexican study. The selection of patients and controls of the GEA study has been described previously [16]. Demographic, clinical, anthropometric, and biochemical parameters, as well as cardiovascular risk factors, were evaluated in patients and controls.

2.2. Genetic Analysis. Genomic DNA from whole blood containing EDTA was isolated by standard techniques. The rs11573185, rs2148911, and rs11573191 single nucleotide polymorphisms (SNPs) of the PLA2G5 were genotyped using $5^{\prime}$ exonuclease TaqMan genotyping assays on an ABI Prism 7900HT Fast Real-Time PCR system, according to manufacturer's instructions (Applied Biosystems, Foster City, CA, USA).

2.3. Statistical Analysis. All calculations were performed using SPSS version 18.0 (SPSS, Chicago, IL) statistical package. Means \pm SD and frequencies of baseline characteristics were calculated. Chi-square tests were used to compare frequencies and ANOVA and Student's $t$-test were used to compare means. ANCOVA was used to determine associations between the polymorphisms and metabolic variables, adjusting for age, gender, and BMI, as appropriate. Logistic regression analysis was used to test for associations of polymorphisms with premature CAD under inheritance models. The most appropriate inheritance model was selected based on Akaike information criteria and was adjusted for age, gender, and BMI. Genotype frequencies did not show deviation from Hardy-Weinberg equilibrium (HWE, $P>$ 0.05). Pairwise linkage disequilibrium (LD, $\left.D^{\prime}\right)$ estimations between polymorphisms and haplotype reconstruction were performed with Haploview version 4:1 (Broad Institute of Massachusetts Institute of Technology and Harvard University, Cambridge, MA, USA).

2.4. Functional Prediction Analysis. We predicted the potential effect of the PLA2G5 SNPs using the TFSearch program (http://www.cbrc.jp/research/db/TFSEARCH.html).

\section{Results}

General characteristics of the population studied are shown in Tables 1 and 2.

3.1. Association of Polymorphisms with Premature CAD. Observed and expected frequencies in the polymorphic sites were in HWE. Similar distribution of the rs11573185 and rs2148911 polymorphisms was observed in both groups. Under dominant, recessive, and additive models adjusting for age, gender, and BMI, the rs11573191 polymorphism was associated with increased risk of premature CAD as compared to controls (OR $=1.51,95 \% \mathrm{CI}: 1.14-1.99, P_{\text {dom }}$ $=3.5 \times 10^{-3} ; \mathrm{OR}=2.95,95 \% \mathrm{CI}: 1.12-3.76, P_{\mathrm{rec}}=0.023$; OR $=1.51,95 \%$ CI: $1.17-1.94, P_{\text {add }}=1.2 \times 10^{-3}$ ) (Table 3 ). The statistical power estimated with QUANTO software (http://hydra.usc.edu/GxE/) to detect an association between premature CAD and controls was 0.88 for rs11573191.

3.2. Association of the Polymorphisms with Metabolic Parameters and Cardiovascular Risk Factors. The effect of the three polymorphisms on various metabolic parameters and cardiovascular risk factors was analyzed in premature CAD patients and controls. No associations were observed in this analysis (data is not shown).

3.3. Haplotype Analysis and Functional Effect. The three PLA2G5 polymorphisms were in strong linkage disequilibrium $\left(D^{\prime}>0.95\right)$ and four haplotypes were observed: $A G G$, $C G G, C A G$, and $C G A$. The $C G A$ haplotype was associated with increased risk of premature CAD $(\mathrm{OR}=1.49,95 \% \mathrm{CI}$ : $1.15-1.93$, and $P=0.0023$ ) (Table 4 ). The effect of the haplotypes on diverse metabolic parameters and cardiovascular risk factors was analyzed in premature CAD patients and healthy controls. Only the CGA haplotype was associated with increased risk of hypertension in the group of patients 
TABLE 1: Demographic characteristics of the studied population.

\begin{tabular}{|c|c|c|c|}
\hline & $\begin{array}{l}\text { Controls } \\
(n=749)\end{array}$ & $\begin{array}{c}\text { Premature CAD } \\
(n=707)\end{array}$ & $P$ \\
\hline Age (years) & $53.99 \pm 9.82$ & $53.3 \pm 7.4$ & 0.982 \\
\hline Gender ( $\%$ male $)$ & 49.7 & 81.4 & $<0.0001$ \\
\hline Body mass index $\left(\mathrm{kg} / \mathrm{m}^{2}\right)$ & $28.47 \pm 4.44$ & $28.77 \pm 4.29$ & 0.184 \\
\hline Obesity (\%) & 31.5 & 35.3 & 0.067 \\
\hline Waist circumference $(\mathrm{cm})$ & $94.38 \pm 11.62$ & $98.06 \pm 11.32$ & $<0.0001$ \\
\hline Central obesity (\%) & 79.7 & 82 & 0.144 \\
\hline Total abdominal fat $\left(\mathrm{cm}^{2}\right)$ & $438.44 \pm 163.17$ & $424.59 \pm 166.62$ & 0.110 \\
\hline Subcutaneous abdominal fat $\left(\mathrm{cm}^{2}\right)$ & $181.30 \pm 120.63$ & $248.95 \pm 110.14$ & $<0.0001$ \\
\hline Visceral abdominal fat $\left(\mathrm{cm}^{2}\right)$ & $157.09 \pm 70.70$ & $175.71 \pm 81.70$ & $<0.0001$ \\
\hline Visceral/subcutaneous adipose tissue ratio & $1.99 \pm 1.00$ & $1.54 \pm 0.81$ & $<0.0001$ \\
\hline Current smokers (\%) & 21.4 & 12.3 & $<0.0001$ \\
\hline Former smokers (\%) & 36.8 & 64.4 & $<0.0001$ \\
\hline Hypertension (\%) & 24.9 & 64.9 & $<0.0001$ \\
\hline Hypertensive medication (\%) & 11.2 & 89.9 & $<0.0001$ \\
\hline Diastolic blood pressure $(\mathrm{mmHg})$ & $74.53 \pm 10.09$ & $74.16 \pm 10.25$ & 0.497 \\
\hline Systolic blood pressure $(\mathrm{mmHg})$ & $121.56 \pm 18.83$ & $121.48 \pm 19.45$ & 0.942 \\
\hline Heart rate (bpm) & $65.54 \pm 9.20$ & $64.99 \pm 11.00$ & 0.301 \\
\hline
\end{tabular}

Data are expressed as means $\pm \mathrm{SD}$; log-transformed values were used for statistical analysis.

$P$ values were estimated using ANOVA for continuous variables and Pearson's Chi-square test for categorical values.

CAD: coronary artery disease.

TABLE 2: Comparison of biochemical parameters in individuals with premature coronary artery disease and controls.

\begin{tabular}{|c|c|c|c|}
\hline & $\begin{array}{l}\text { Controls } \\
(n=749)\end{array}$ & $\begin{array}{c}\text { Premature CAD } \\
(n=707)\end{array}$ & $P$ \\
\hline Total cholesterol (mg/dL) & $19338 \pm 36.46$ & $169.31 \pm 48.18$ & $<0.0001$ \\
\hline $\mathrm{TC}>200 \mathrm{mg} / \mathrm{dL}(\%)$ & 40.0 & 20.7 & $<0.0001$ \\
\hline HDL-C (mg/dL) & $46.61 \pm 13.69$ & $39.90 \pm 10.82$ & $<0.0001$ \\
\hline Hipo-a-lipoproteinemia (\%) & 51.2 & 57.5 & 0.009 \\
\hline LDL-C (mg/dL) & $118.69 \pm 32.37$ & $97.22 \pm 40.25$ & $<0.0001$ \\
\hline Triglycerides (mg/dL) & $170.47 \pm 113.01$ & $193.72 \pm 127.26$ & $<0.0001$ \\
\hline Hypertriglyceridemia (\%) & 46.9 & 59.8 & $<0.0001$ \\
\hline ApoAI (mg/dL) & $139.50 \pm 43.68$ & $119.32 \pm 26.74$ & $<0.0001$ \\
\hline ApoB (mg/dL) & $91.32 \pm 28.85$ & $82.71 \pm 31.01$ & $<0.0001$ \\
\hline Statin and/or fibrate treatment (\%) & 4.2 & 15.4 & $<0.0001$ \\
\hline Type 2 diabetes mellitus (\%) & 7.6 & 35.3 & $<0.0001$ \\
\hline Glucose (mg/dL) & $100.75 \pm 35.75$ & $112.33 \pm 44.31$ & 0.001 \\
\hline HOMA-IR & $5.29 \pm 8.38$ & $6.73 \pm 6.00$ & $<0.0001$ \\
\hline Insulin $(\mu \mathrm{U} / \mathrm{mL})$ & $20.32 \pm 13.82$ & $24.23 \pm 17.26$ & $<0.0001$ \\
\hline Metabolic syndrome (\%) & 46.3 & 46.1 & 0.488 \\
\hline Uric acid (mg/dL) & $5.47 \pm 1.78$ & $6.07 \pm 2.06$ & $<0.0001$ \\
\hline Creatinine $(\mathrm{mg} / \mathrm{dL})$ & $0.84 \pm 0.25$ & $0.92 \pm 0.31$ & $<0.0001$ \\
\hline Alanine transaminase (IU/L) & $27.75 \pm 12.43$ & $28.07 \pm 11.49$ & 0.619 \\
\hline Aspartate transaminase (IU/L) & $26.84 \pm 11.34$ & $27.97 \pm 17.77$ & 0.222 \\
\hline Alkaline phosphatase (IU/L) & $83.07 \pm 28.36$ & $78.99 \pm 25.97$ & 0.004 \\
\hline Gamma-glutamyl transpeptidase (IU/L) & $35.91 \pm 32.83$ & $44.36 \pm 44.63$ & $<0.0001$ \\
\hline
\end{tabular}

Data are expressed as means $\pm \mathrm{SD}$; log-transformed values were used for statistical analysis.

$P$ values were estimated using ANOVA for continuous variables and Pearson's Chi-square test for categorical values.

CAD: coronary artery disease. 
TABLE 3: Association of the rs11573185, rs2148911, and rs11573191 PLA2G5 gene polymorphisms with premature CAD.

\begin{tabular}{|c|c|c|c|c|c|c|c|}
\hline \multirow{2}{*}{ rs11573185 } & \multicolumn{3}{|c|}{ Genotype frequency (\%) } & \multirow{2}{*}{ MAF } & \multirow{2}{*}{ Model } & \multirow{2}{*}{ OR (95\% CI) } & \multirow{2}{*}{$P$} \\
\hline & $\mathrm{A} / \mathrm{A}$ & $\mathrm{A} / \mathrm{C}$ & $\mathrm{C} / \mathrm{C}$ & & & & \\
\hline Control $(n=749)$ & 0.410 & 0.437 & 0.153 & 0.371 & & & \\
\hline Premature CAD $(n=707)$ & 0.395 & 0.462 & 0.142 & 0.373 & $\begin{array}{c}\text { Dominant } \\
\text { additive }\end{array}$ & $\begin{array}{l}1.21(0.97-1.52) \\
1.10(0.94-1.28)\end{array}$ & $\begin{array}{l}0.089 \\
0.250\end{array}$ \\
\hline \multirow{2}{*}{ rs 2148911} & \multicolumn{3}{|c|}{ Genotype frequency (\%) } & MAF & Model & OR (95\% CI) & $P$ \\
\hline & $\mathrm{G} / \mathrm{G}$ & $\mathrm{G} / \mathrm{A}$ & $\mathrm{A} / \mathrm{A}$ & & & (3) & \\
\hline Control $(n=749)$ & 0.780 & 0.206 & 0.015 & 0.117 & & & \\
\hline Premature CAD $(n=707)$ & 0.782 & 0.203 & 0.014 & 0.115 & $\begin{array}{l}\text { Dominant } \\
\text { additive }\end{array}$ & $\begin{array}{l}1.08(0.83-1.41) \\
1.07(0.84-1.36)\end{array}$ & $\begin{array}{l}0.560 \\
0.610\end{array}$ \\
\hline \multirow{2}{*}{ rs11573191 } & \multicolumn{3}{|c|}{ Genotype frequency (\%) } & MAF & Model & OR $(95 \% \mathrm{CI})$ & $P$ \\
\hline & $\mathrm{G} / \mathrm{G}$ & G/A & $\mathrm{A} / \mathrm{A}$ & & & & \\
\hline Control $(n=749)$ & 0.825 & 0.166 & 0.009 & 0.092 & & & \\
\hline Premature CAD $(n=707)$ & 0.777 & 0.202 & 0.021 & 0.122 & $\begin{array}{c}\text { Dominant } \\
\text { recessive } \\
\text { additive }\end{array}$ & $\begin{array}{l}1.51(1.14-1.99) \\
2.95(1.12-3.76) \\
1.51(1.17-1.94)\end{array}$ & $\begin{array}{c}3.5 \times 10^{-3} \\
0.023 \\
1.2 \times 10^{-3} \\
\end{array}$ \\
\hline
\end{tabular}

Associations were tested using logistic regression adjusting for age, gender, and BMI.

CAD: coronary artery disease; MAF: minor allele frequency.

TABLE 4: Haplotype frequencies in premature CAD patients and healthy controls.

\begin{tabular}{|c|c|c|c|c|c|c|c|}
\hline \multirow{2}{*}{ rs11573185 } & \multirow{2}{*}{ rs2148911 } & \multirow{2}{*}{ rs11573191 } & \multicolumn{3}{|c|}{ Frequencies } & \multirow{2}{*}{ OR $(95 \% \mathrm{CI})$} & \multirow{2}{*}{$P$} \\
\hline & & & Total & Control & Premature CAD & & \\
\hline $\bar{A}$ & G & $G$ & 0.625 & 0.625 & 0.6256 & 1 & - \\
\hline C & $G$ & $G$ & 0.151 & 0.165 & 0.1367 & $0.86(0.69-1.08)$ & 0.19 \\
\hline C & $A$ & $G$ & 0.115 & 0.115 & 0.1153 & $1.12(0.88-1.44)$ & 0.36 \\
\hline C & $G$ & $A$ & 0.105 & 0.091 & 0.1207 & $1.49(1.15-1.93)$ & 0.0023 \\
\hline
\end{tabular}

The ORs were adjusted for age, gender, medication, and BMI.

The AGG haplotype was used as reference.

with premature CAD (OR $=1.75,95 \% \mathrm{CI}: 1.17-2.60$, and $P=$ 0.0072 ) (data is not shown). This analysis was adjusted for age, gender, medication, and BMI.

Based on SNP functional prediction software, the rs11573191 polymorphism seems to be functional. This polymorphism modifies the binding affinity of the transcriptional factor MZF1, having greater affinity by the $A$ allele. The differences in affinity could have important consequences in the expression of $\mathrm{SPLA}_{2}-\mathrm{V}$ protein.

\section{Discussion}

The role of sPLA 2 -IIA in atherogenesis has been well studied; however, the involvement of $s \mathrm{PLA}_{2}-\mathrm{V}$ is less understood. sPLA $_{2}-\mathrm{V}$ is highly expressed in the heart and is present in other tissues as well, including eye, placenta, lung, and brain [17-21]. A number of human cells, including macrophages, neutrophils, bronchial and renal tubular epithelia, subendocardial cells (cardiomyocytes), and interstitial fibroblasts of gastric submucosa, have been shown to express $\mathrm{sPLA}_{2}$ $\mathrm{V}$ [20, 22-26]. Recently, Ohta et al. [27] identified a unique function of $\mathrm{SPLA}_{2}-\mathrm{V}$ in activation of macrophages and in their capacity to recruit $T$ cells to amplify the effector phase of pulmonary inflammation. However, the possible effect of the $\mathrm{sPLA}_{2}-\mathrm{V}$ in the developing of atherosclerosis is contradictory.
Enzyme deficiency in $\mathrm{PLA}_{2}-\mathrm{V}$-null mice leads to marked attenuation of airway inflammation $[28,29]$ and reduced atherosclerosis $[9,30]$. It has been reported that $\mathrm{SPLA}_{2}-\mathrm{V}$ can hydrolyze phospholipids in LDL, leading to the production of proatherogenic modified LDL in vitro [7]. PLA2G5 overexpression in bone marrow cells worsens atherosclerosis, whereas its deficiency decreases modestly the atherosclerosis [9]. In the same way, the PLA2G5 deficiency does not affect the atherosclerotic lesion development in mice [30] and pan-sPLA2 inhibitor varespladib did not reduce the risk of cardiovascular events after acute coronary syndrome [31]. The genes that encode $s \mathrm{PLA}_{2}$-IIA and $\mathrm{PLA}_{2}-\mathrm{V}$ molecules are linked in a negative orientation on the same chromosome [14]. Polymorphisms in both genes have been associated with variations in the lipid levels $[15,32]$. In the present work, three PLA2G5 gene polymorphisms (rs11573185, rs2148911, and rs11573191) were analyzed in order to establish their role as susceptibility markers for premature CAD, metabolic parameters, and cardiovascular risk factors. The functional prediction software used here predicted that the rs11573191 polymorphism is functional with an effect on the affinity of the sequence for the MZF1 transcriptional factor. The $A$ allele of this polymorphism presents major affinity for the transcription factor than the $G$ allele, having important consequences on $\mathrm{SPLA}_{2}-\mathrm{V}$ production. This result obtained 
using informatics software is in agreement with our genetic results because, in the association analysis, the rs11573191 $A$ allele was associated with increased risk of developing premature CAD. However, our study did not include expression analysis and we have no evidence that the PLA2G5 expression is different in premature CAD patients with the risk allele. The distribution of the other two PLA2G5 polymorphisms was similar in CAD patients and healthy controls. Recently, Holmes et al. [33] using data from the Advanced Study of Aortic Pathology identified that the PLA2G5 rs525380 polymorphism was strongly associated with PLA2G5 mRNA expression levels. However, the association of this polymorphism with sPLA activity and coronary heart disease was not corroborated. This polymorphism was not included in our analysis. Wootton et al. [15] studied seven PLA2G5 polymorphisms in patients with type II diabetes mellitus to investigate the association of these polymorphisms with coronary heart disease risk factors. Of the seven SNPs, three of them (rs11573185, rs11573203, and rs11573248) showed significant association with cholesterol and LDL levels. In our study, none of the studied polymorphisms was associated with lipid levels in premature CAD or healthy controls. In the study by Wootton et al. [15], the haplotype analysis showed associations of some haplotypes with significantly higher cholesterol and LDL. In our work, the three studied polymorphisms were in linkage disequilibrium, and one of the haplotypes (CGA) was associated with risk of developing premature $\mathrm{CAD}$ and with hypertension in the premature CAD patients. This haplotype included the $A$ allele associated independently with the disease. In a previous work, Mancini et al. [34], using a genome-wide association analysis in a spontaneously hypertensive rat model, identified four candidate genes for hypertension, one of them was the PLA2G5 gene. This agrees with our study, in which an association of the PLA2G5 haplotype with hypertension was detected.

Study limitations need to be addressed. This study only included the analysis of three polymorphisms of the PLA2G5 gene. Considering that this is the first work to report an association of the PLA2G5 polymorphisms with premature CAD and hypertension, replication in another group of patients is necessary. The predicted functional consequences of the rs 11573191 polymorphism, using informatics tools, need experimental testing.

\section{Conclusion}

In summary, our study demonstrates the association of the PLA2G5 rs11573191 polymorphism with premature CAD and with hypertension in this group of patients. According to the informatics software, this polymorphism had a functional effect in modifying the affinity of the sequence by the MZF1 transcription factor. The associations reported in the present work should be explored in other populations to establish the true role of these polymorphisms in cardiovascular diseases.

\section{Conflict of Interests}

The authors declare that there is no conflict of interests regarding the publication of this paper.

\section{Acknowledgments}

The authors thank all the volunteers who participated in this study. This work was supported by Grant from the Consejo Nacional de Ciencia y Tecnología (Project no. 156911).

\section{References}

[1] R. Ross, "Atherosclerosis-an inflammatory disease," The New England Journal of Medicine, vol. 340, no. 2, pp. 115-126, 1999.

[2] X. García-Moll, "Inflammatory and anti-inflammatory markers in acute coronary syndromes. Ready for use in the clinical setting?" Revista Espanola de Cardiologia, vol. 58, no. 6, pp. 615617, 2005

[3] A. J. Lusis, "Atherosclerosis," Nature, vol. 407, no. 6801, pp. $233-$ 241, 2000.

[4] D. A. Six and E. A. Dennis, "The expanding superfamily of phospholipase $\mathrm{A}_{2}$ enzymes: classification and characterization," Biochimica et Biophysica Acta, vol. 1488, no. 1-2, pp. 1-19, 2000.

[5] E. Hurt-Camejo, S. Andersen, R. Standal et al., "Localization of nonpancreatic secretory phospholipase $A_{2}$ in normal and atherosclerotic arteries. Activity of the isolated enzyme on lowdensity lipoproteins," Arteriosclerosis, Thrombosis, and Vascular Biology, vol. 17, pp. 300-309, 1997.

[6] K. Hanasaki, K. Yamada, S. Yamamoto et al., "Potent modification of low density lipoprotein by group $\mathrm{X}$ secretory phospholipase $\mathrm{A}_{2}$ is linked to macrophage foam cell formation," Journal of Biological Chemistry, vol. 277, no. 32, pp. 29116-29124, 2002.

[7] B. B. Boyanovsky, D. R. Van Der Westhuyzen, and N. R. Webb, "Group V secretory phospholipase $\mathrm{A}_{2}$-modified low density lipoprotein promotes foam cell formation by a SR-A- and CD36independent process that involves cellular proteoglycans," Journal of Biological Chemistry, vol. 280, no. 38, pp. 32746-32752, 2005.

[8] B. Ivandic, L. W. Castellani, X.-P. Wang et al., "Role of group II secretory phospholipase $\mathrm{A}_{2}$ in atherosclerosis: 1 . Increased atherogenesis and altered lipoproteins in transgenic mice expressing group IIa phospholipase $\mathrm{A}_{2}$," Arteriosclerosis, Thrombosis, and Vascular Biology, vol. 19, no. 5, pp. 1284-1290, 1999.

[9] M. A. Bostrom, B. B. Boyanovsky, C. T. Jordan et al., "Group V secretory phospholipase $\mathrm{A}_{2}$ promotes atherosclerosis: evidence from genetically altered mice," Arteriosclerosis, Thrombosis, and Vascular Biology, vol. 27, no. 3, pp. 600-606, 2007.

[10] H. Ait-Oufella, O. Herbin, C. Lahoute et al., "Group X secreted phospholipase $\mathrm{A}_{2}$ limits the development of atherosclerosis in LDL receptor-null mice," Arteriosclerosis, Thrombosis, and Vascular Biology, vol. 33, pp. 466-473, 2013.

[11] H. Sato, R. Kato, Y. Isogai et al., "Analyses of group III secreted phospholipase $\mathrm{A}_{2}$ transgenic mice reveal potential participation of this enzyme in plasma lipoprotein modification, macrophage foam cell formation, and atherosclerosis," Journal of Biological Chemistry, vol. 283, no. 48, pp. 33483-33497, 2008.

[12] Y. Ishimoto, K. Yamada, S. Yamamoto, T. Ono, M. Notoya, and K. Hanasaki, "Group V and X secretory phospholipase $\mathrm{A}_{2} \mathrm{~s}$-induced modification of high-density lipoprotein linked to the reduction of its antiatherogenic functions," Biochimica et Biophysica Acta, vol. 1642, no. 3, pp. 129-138, 2003.

[13] B. Rosengren, H. Peilot, M. Umaerus et al., "Secretory phospholipase $\mathrm{A}_{2}$ group $\mathrm{V}$ : lesion distribution, activation by arterial 
proteoglycans, and induction in aorta by a western diet," Arteriosclerosis, Thrombosis, and Vascular Biology, vol. 26, no. 7, pp. 1579-1585, 2006.

[14] J. A. Tischfield, Y. R. Xia, D. M. Shih et al., "Low-molecular weight, calciumdependent phospholipase $\mathrm{A}_{2}$ genes are linked and map to homologous chromosome regions in mouse and human," Genomics, vol. 32, pp. 328-333, 1996.

[15] P. T. E. Wootton, N. L. Arora, F. Drenos et al., “Tagging SNP haplotype analysis of the secretory PLA2-V gene, PLA2G5, shows strong association with LDL and oxLDL levels, suggesting functional distinction from sPLA2-IIA: results from the UDACS study," Human Molecular Genetics, vol. 16, no. 12, pp. 1437-1444, 2007.

[16] T. Villarreal-Molina, C. Posadas-Romero, S. Romero-Hidalgo et al., "The ABCA1 gene R230C variant is associated with decreased risk of premature coronary artery disease: the genetics of atherosclerotic disease (GEA) study," PLoS ONE, vol. 7, Article ID e49285, 2012.

[17] E. Valentin, A. G. Singer, F. Ghomashchi, M. Lazdunski, M. H. Gelb, and G. Lambeau, "Cloning and recombinant expression of human group IIF-secreted phospholipase $\mathrm{A}_{2}$," Biochemical and Biophysical Research Communications, vol. 279, no. 1, pp. 223228, 2000.

[18] M. Kolko, N. R. Christoffersen, S. G. Barreiro, and N. G. Bazan, "Expression and location of mRNAs encoding multiple forms of secretory phospholipase $\mathrm{A}_{2}$ in the rat retina," Journal of Neuroscience Research, vol. 77, no. 4, pp. 517-524, 2004.

[19] L. Cupillard, K. Koumanov, M. G. Mattéi, M. Lazdunski, and G. Lambeau, "Cloning, chromosomal mapping, and expression of a novel human secretory phospholipase $\mathrm{A}_{2}$," The Journal of Biological Chemistry, vol. 272, pp. 15745-15752, 1997.

[20] M. C. Seeds, K. A. Jones, R. D. Hite et al., "Cell-specific expression of Group X and Group V secretory phospholipases $\mathrm{A}_{2}$ in human lung airway epithelial cells," American Journal of Respiratory Cell and Molecular Biology, vol. 23, no. 1, pp. 37-44, 2000.

[21] N. Suzuki, J. Ishizaki, Y. Yokota et al., "Structures, enzymatic properties, and expression of novel human and mouse secretory phospholipase $\mathrm{A}_{2} \mathrm{~s}$," Journal of Biological Chemistry, vol. 275, no. 8, pp. 5785-5793, 2000.

[22] S. Masuda, M. Murakami, Y. Ishikawa, T. Ishii, and I. Kudo, "Diverse cellular localizations of secretory phospholipase $A_{2}$ enzymes in several human tissues," Biochimica et Biophysica Acta, vol. 1736, no. 3, pp. 200-210, 2005.

[23] S. Masuda, M. Murakami, M. Mitsuishi et al., "Expression of secretory phospholipase $A_{2}$ enzymes in lungs of humans with pneumonia and their potential prostaglandin-synthetic function in human lung-derived cells," Biochemical Journal, vol. 387, no. 1, pp. 27-38, 2005.

[24] K. P. Kim, J. D. Rafter, L. Bittova et al., "Mechanism of human group V phospholipase $\mathrm{A}_{2}$ (PLA2)-induced leukotriene biosynthesis in human neutrophils: a potential role of heparan sulfate binding in PLA2 internalization and degradation," Journal of Biological Chemistry, vol. 276, no. 14, pp. 11126-11134, 2001.

[25] B. Balestrieri and J. P. Arm, "Group V sPLA2: classical and novel functions," Biochimica et Biophysica Acta, vol. 1761, no. 11, pp. 1280-1288, 2006.

[26] M. Murakami, S. Masuda, S. Shimbara, Y. Ishikawa, T. Ishii, and I. Kudo, "Cellular distribution, post-translational modification, and tumorigenic potential of human group III secreted phospholipase $\mathrm{A}_{2}$," Journal of Biological Chemistry, vol. 280, no. 26, pp. 24987-24998, 2005.
[27] S. Ohta, M. Imamura, W. Xing, J. A. Boyce, and B. Balestrieri, "Group V secretory phospholipase $A_{2}$ is involved in macrophage activation and is sufficient for macrophage effector functions in allergic pulmonary inflammation," The Journal of Immunology, vol. 190, pp. 5927-5938, 2013.

[28] N. M. Muñoz, A. Y. Meliton, J. P. Arm, J. V. Bonventre, W. Cho, and A. R. Leff, "Deletion of secretory group V phospholipase $\mathrm{A}_{2}$ attenuates cell migration and airway hyperresponsiveness in immunosensitized mice," Journal of Immunology, vol. 179, no. 7, pp. 4800-4807, 2007.

[29] G. Giannattasio, D. Fujioka, W. Xing, H. R. Katz, J. A. Boyce, and B. Balestrieri, "Group v secretory phospholipase $\mathrm{A}_{2}$ reveals its role in house dust mite-induced allergic pulmonary inflammation by regulation of dendritic cell function," Journal of Immunology, vol. 185, no. 7, pp. 4430-4438, 2010.

[30] B. Boyanovsky, M. Zack, K. Forrest, and N. R. Webb, “The capacity of group $\mathrm{V}$ sPLA 2 to increase atherogenicity of $\mathrm{ApoE}^{-/-}$and $\mathrm{LDLR}^{-/-}$mouse LDL in vitro predicts its atherogenic role in vivo," Arteriosclerosis, Thrombosis, and Vascular Biology, vol. 29, no. 4, pp. 532-538, 2009.

[31] S. J. Nicholls, J. J. Kastelein, G. G. Schwartz et al., "Varespladib and cardiovascular events in patients with acute coronary syndrome: the VISTA-16 randomized clinical trial," JAMA, vol. 311, pp. 252-262, 2014.

[32] P. T. E. Wootton, F. Drenos, J. A. Cooper et al., "Tagging-SNP haplotype analysis of the secretory PLA $\mathrm{A}_{2}$ IIa gene PLA2G2A shows strong association with serum levels of sPLA $\mathrm{AI}_{2}$ : results from the UDACS study," Human Molecular Genetics, vol. 15, no. 2, pp. 355-361, 2006.

[33] M. V. Holmes, H. J. Exeter, L. Folkersen et al., "Novel genetic approach to investigate the role of plasma secretory phospholipase $\mathrm{A}_{2}\left(\mathrm{sPLA}_{2}\right)-\mathrm{V}$ isoenzyme in coronary herat disease," Circulation: Cardiovascular Genetics, vol. 7, pp. 144-150, 2014.

[34] M. Mancini, E. Petretto, C. Kleinert et al., "Mapping genetic determinants of coronary microvascular remodeling in the spontaneously hypertensive rat," Basic Research in Cardiology, vol. 108, p. 316, 2013. 

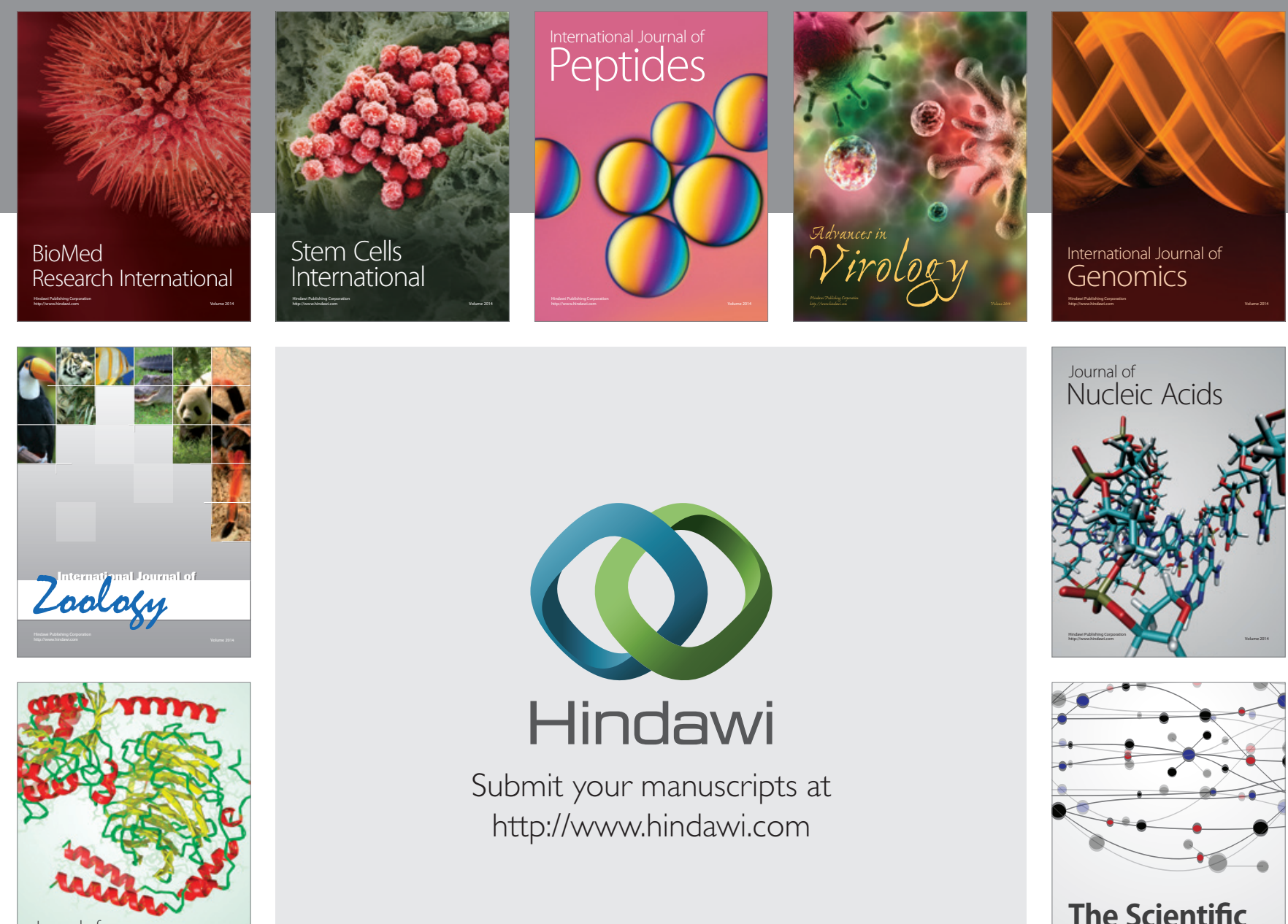

Submit your manuscripts at

http://www.hindawi.com

Journal of
Signal Transduction
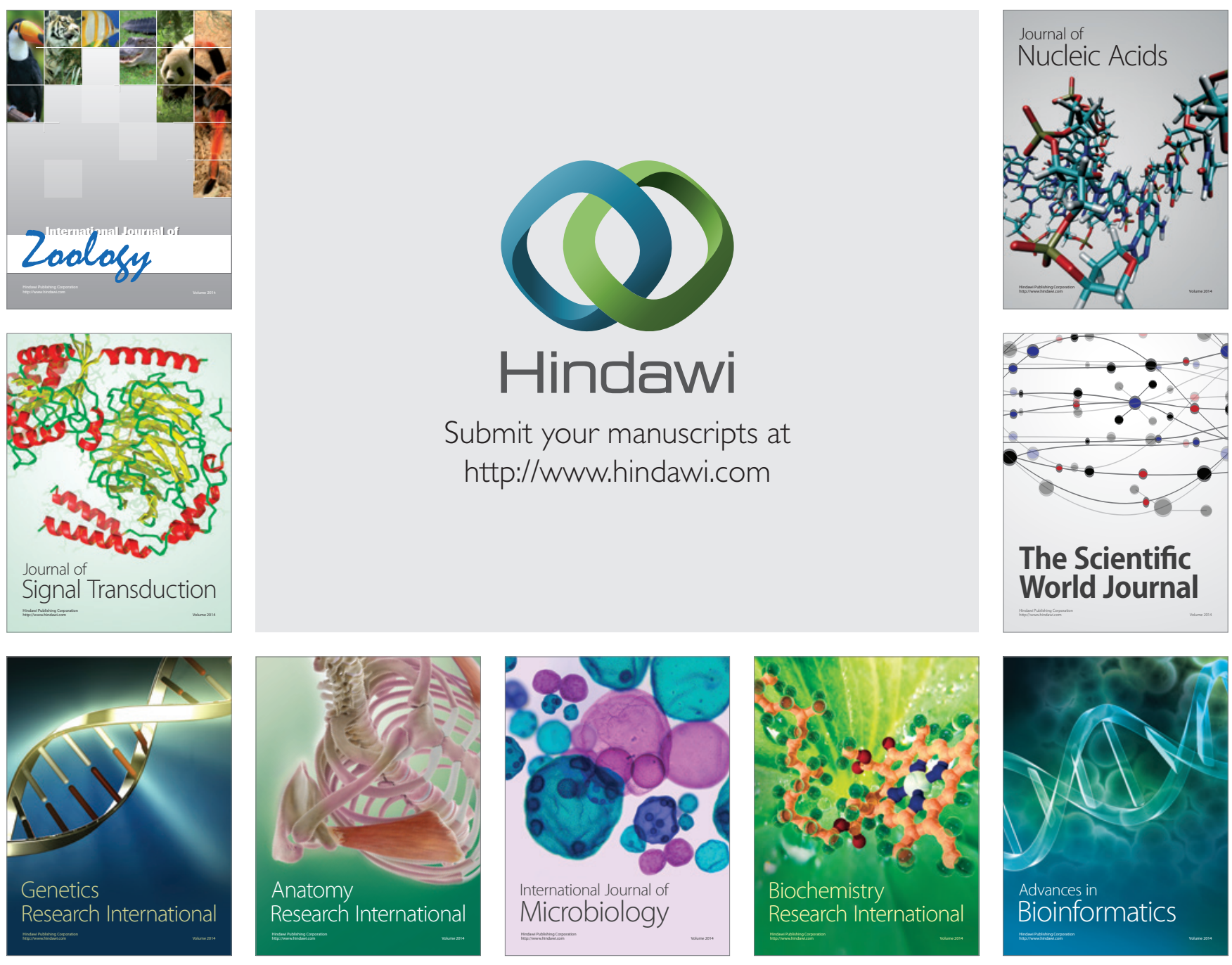

The Scientific World Journal
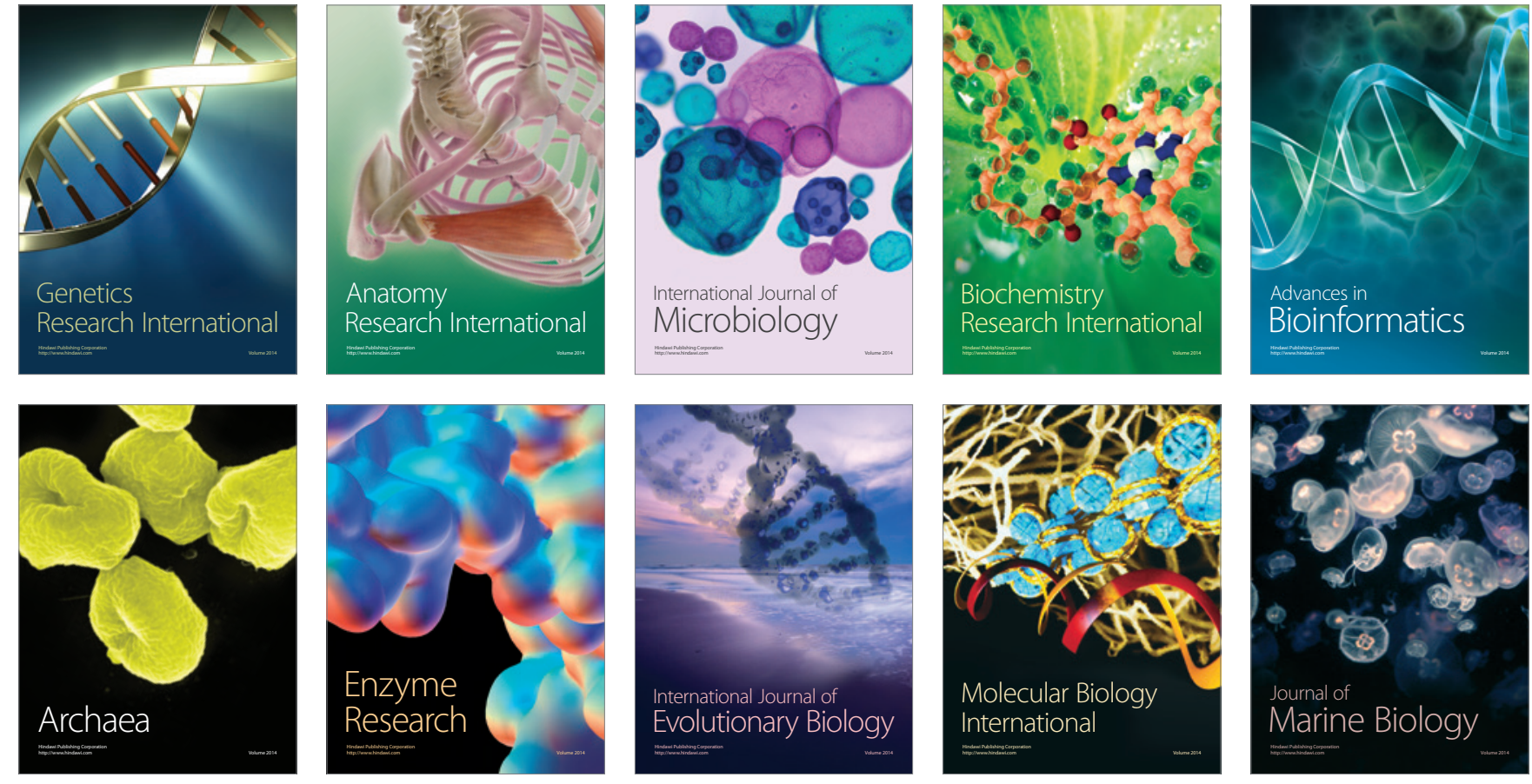